\title{
KOMPOSISI HASIL TANGKAPAN IKAN YANG TERTANGKAP DI SEKITAR RUMPON ATRAKTOR IJUK DI PERAIRAN KABUPATEN NAGAN RAYA PROVINSI ACEH
}

\section{COMPOSITION OF FISH CATCHING AROUND PALM FIBER FISH AGGREGATING DEVICE IN NAGAN RAYA WATERS ACEH PROVINCE}

\author{
Hafinuddin $^{*}$, M. Agam Thahir', Roza Yusfiandayani², Mulyono S. Baskoro², Indra Jaya ${ }^{3}$, \\ Isma Sari ${ }^{4}$, Mardhiah ${ }^{4}$ \\ ${ }^{1}$ Program Studi Perikanan Fakultas Perikanan dan Ilmu Kelautan Universitas Teuku Umar, \\ Meulaboh, Indonesia. \\ ${ }^{2}$ Departemen Pemanfaatan Sumberdaya Perikanan Fakultas Perikanan dan Ilmu Kelautan IPB \\ University, Indonesia. \\ ${ }^{3}$ Departemen Ilmu dan Teknologi Kelautan Fakultas Perikanan dan Ilmu Kelautan IPB University, \\ Indonesia. \\ ${ }^{4}$ Mahasiswa Program Studi Perikanan Fakultas Perikanan dan Ilmu Kelautan Universitas Teuku \\ Umar, Meulaboh, Indonesia \\ *korespondensi: hafinuddin@utu.ac.id
}

\begin{abstract}
The study was conducted to investigate composition of fish catching around palm fiber fish aggregating device (FAD). This research was performed in waters of Nagan Raya District, Indian Ocean on October until December 2018. Palm fiber FAD and coconut fronds FAD was set up at 20-30 m depth. The The research is using survey method and to collecting data, experimental fishing was used to collect data with hand line fishing gear. The results show the types of fish catching in palm fiber FAD is Lepturacanthus savala, Selar crumenopthalmus, Selaroides leptolepis, Rastrelliger kanagurta and Sardinella lemuru. For coconut fronds FADs, composition of fish catching is Selaroides leptolepis, Rastrelliger kanagurta, Sardenella sirin, Caranx sp, Terapon jarbua, Chorinemus tala dan Upenius mullocensin. Total of fish cacthing in palm fiber FADs is 70 fish. While at coconut fronds FADs is 29 fish. Based on descriptive analysis, the palm fiber FADs is more effective than coconut fronds FADs. This study is very important in the production of fish catching around FADs.
\end{abstract}

Keywords: FAD, Composition of fish catching, Palm fiber attractor

\section{Pendahuluan}

Nelayan Kabupaten Nagan Raya merupakan didominasi oleh nelayan kecil dimana masih menggunakan armada penangkapan ikan ukuran <5GT dan motor tempel. Alat bantu penangkapan ikan yang biasa mereka gunakan berupa rumpon tetap. Rumpon sangat membantu nelayan dalam menangkap ikan karena kepastian daerah penangkapan ikan. Taquet (2011) menjelaskan bahwa pengunaan teknologi rumpon dapat memaksimalkan hasil tangkapan dan juga rumpon (fish aggregating device/ FAD) memiliki manfaat seperti 1) meningkatkan efesiensi penagkapan; 2) meningkatkan catch unit effort (CPUE); 3) meminimumkan biaya penangkapan 
(terutama bahan bakar minyak). Hafinuddin et al (2015) menjelaskan rumpon juga berpotensi sebagai tempat untuk memijah (nursery ground) pada cumi-cumi dan ikan.

Komponen utama rumpon adalah pelampung (float), tali (rope), pengumpul ikan (attractor) dan pemberat (anchor). Altinagac et al. (2010) menjelaskan bahwa atraktor merupakan salah satu komponen utama pada rumpon karena berfungsi sebagai alat pengumpul ikan sesungguhnya.

Hafinuddin dan Mahendra (2016) menyebutkan bahwa rumpon atraktor ijuk memiliki nilai ekonomis yang lebih tinggi dibandingkan rumpon dengan rumpon atraktor yang menggunakan daun kelapa atau daun pinang. Hal ini dikarenakan biaya pembuatan rumpon atraktor ijuk relatif lebih murah dibandingkan rumpon atraktor daun pinang atau daun kelapa.

Rumpon atraktor ijuk (Arenga pinnata) telah memberikan produktivitas hasil tangkapan yang cenderung sama dengan daun kelapa, namun daya tahan atraktor ijuk lebih baik dari daun kelapa dengan masa perendaman yang sama dilaut (Baihaqi, 2014). Sedangkan menurut Ibrahim et al. (2014) Atraktor daun kelapa hanya mampu bertahan 3 bulan perendaman di laut. Hanya saja penelitian rumpon atraktor ijuk belum pernah dilaksanakan di Kabupaten Nagan Raya di antaranya komposisi ikan yang tertangkap di sekitar rumpon atraktor ijuk. Oleh karena itu, penelitian ini bertujuan untuk mengetahui komposisi hasil tangkapan di sekitar rumpon atraktor ijuk dan rumpon daun kelapa di Perairan Kabupaten Nagan Raya.

\section{Metode Penelitian}

\section{Waktu dan tempat penelitian}

Penelitian ini dilaksanakan pada bulan September - Desember 2018 yang bertempat di Perairan Kabupaten Nagan Raya, Samudera Hindia. Secara Geografis Kabupaten Nagan Raya terletak pada titik koordinat 03043'53,47' 04³7'53,38” LU dan 96¹1'36,11" - 96²4'54,92” BT dengan luas wilayah $3.363,7 \mathrm{~km}$. Lokasi penelitian dapat dilihat pada Gambar 1. 


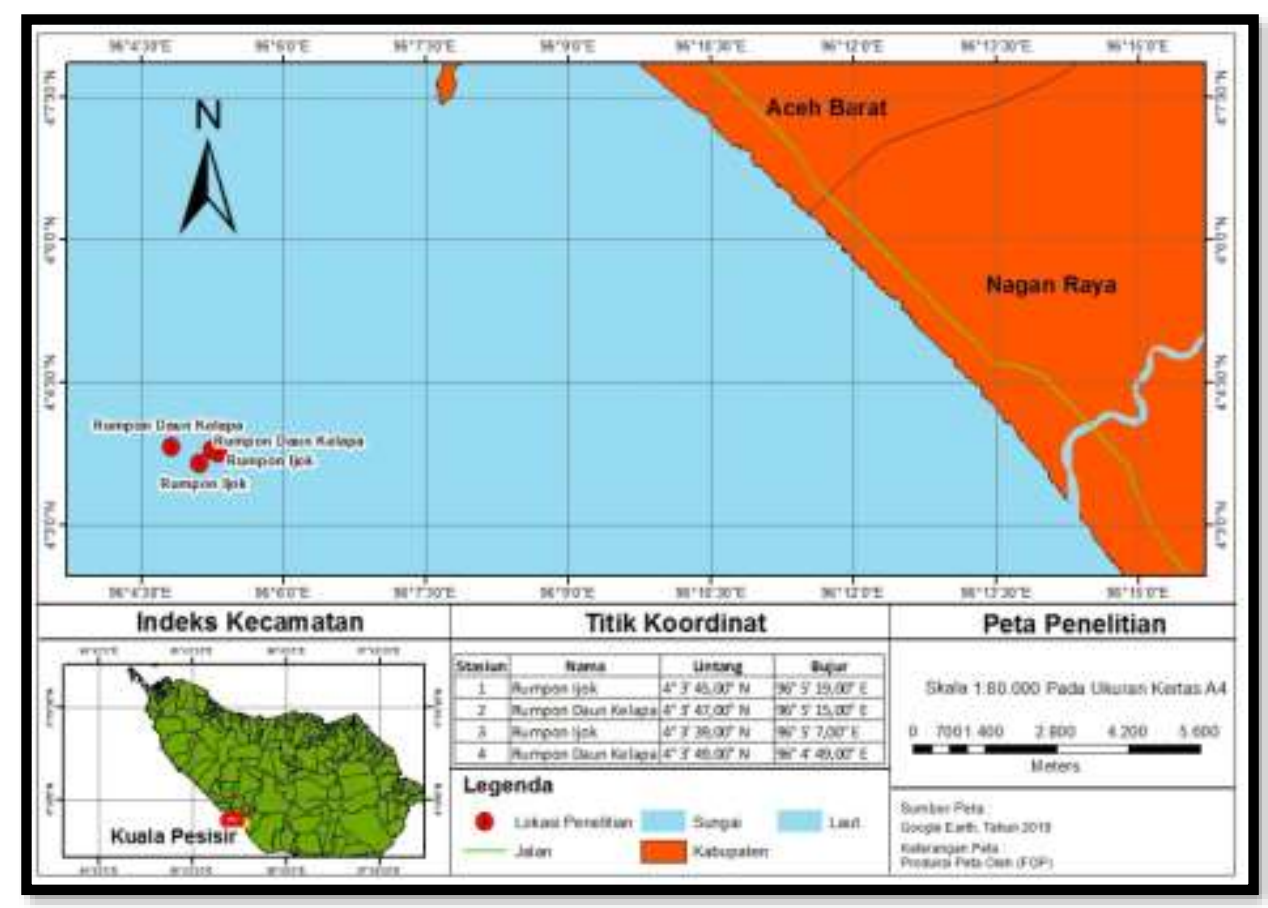

Gambar 1. Peta lokasi peletakan rumpon di Perairan Kabupaten Nagan Raya

\section{Metode Pengumpulan Data}

Metode pengumpulan data adalah dengan metode survei dimana teknik pengumpulan data menggunakan metode experimental fishing. Alat tangkap yang digunakan untuk pengumpulan data yaitu pancing ulur yang dioperasikan disekitar rumpon. Uji penangkapan ikan di sekitar rumpon dengan menggunakan pancing ulur adalah 12 kali ulangan. Adapun jumlah rumpon yang digunakan sebagai objek penelitian adalah 4 unit terdiri atas 2 unit rumpon atraktor ijuk dan dua unit rumpon atraktor daun kelapa sebagai rumpon kontrol. Lokasi pemasangan rumpon atraktor ijuk dan atraktor daun kelapa berada pada kedalaman 15-25 meter.

\section{Analisis Data}

Data yang telah dikumpulkan selanjutnya dianalisis menggunakan analisis deskriptif untuk mengetahui komposisi hasil tangkapan di sekitar rumpon yang ditampilkan dalam bentuk diagram (dalam persentase). Data diolah menggunakan perangkat lunak Microsoft Excel 2010.

\section{Hasil dan Pembahasan}

Hasil penelitian menunjukkan bahwa ikan yang tertangkap menggunakan alat tangkap pancing ulur pada rumpon atraktor ijuk yaitu ikan layur (Lepturacanthus savala), ikan selar mata besar (Selar crumenopthalmus), ikan selar kuning (Selaroides leptolepis), ikan kembung laki-laki (Rastrelliger kanagurta), dan ikan lemuru (Sardinella lemuru). Sedangkan jenis ikan yang tertangkap pada rumpon atraktor daun kelapa yaitu ikan selar ekor kuning (Selaroides leptolepis), ikan 
kembung laki-laki (Rastrelliger kanagurta), ikan tamban (Sardenella sirin), ikan kuwe (Caranx sp), ikan kerong (Terapon jarbua), ikan talang-talang (Chorinemus tala) dan ikan biji nangka (Upenius mullocensin). Komposisi ikan yang tertangkap di sekitar rumpon ijuk dan ikan yang tertangkap di sekitar rumpon atraktor kelapa dapat dilihat pada Gambar 2 dan Gambar 3.



Gambar 2 Jenis dan jumlah ikan yang tertangkap pada rumpon atraktor ijuk

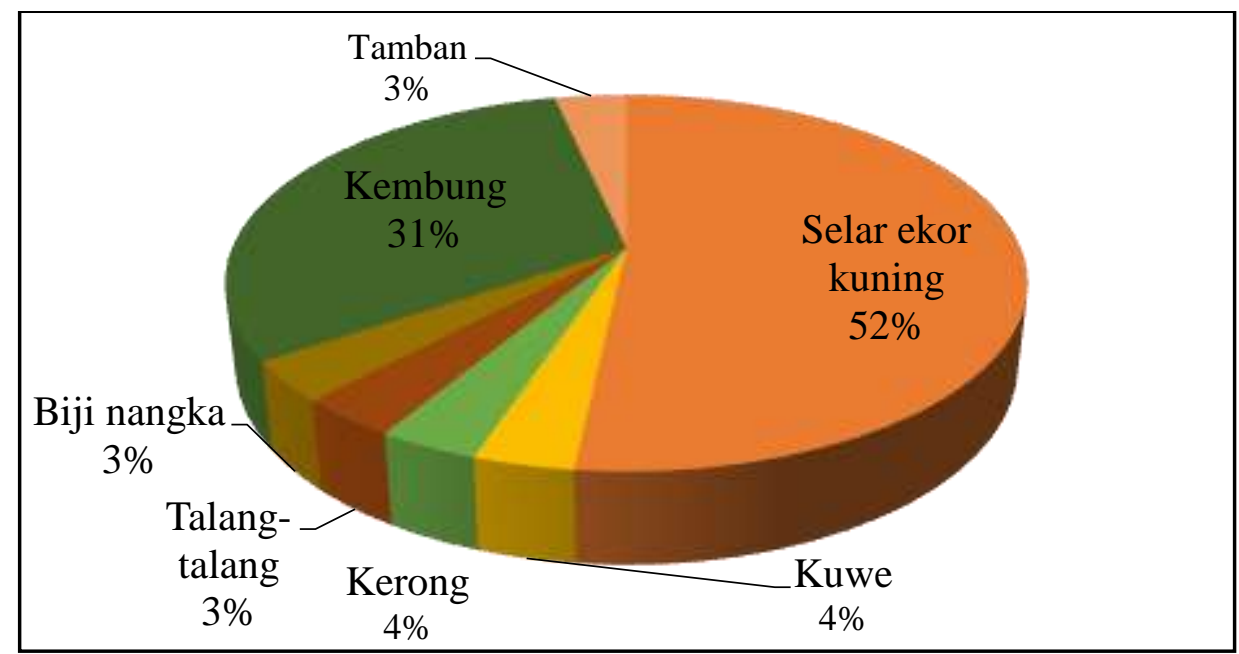

Gambar 3 Jenis dan jumlah ikan yang tertangkap pada rumpon daun kelapa.

Hasil tangkapan pada rumpon atraktor ijuk terdiri atas 5 spesies ikan dan rumpon atraktor daun kelapa sebanyak 7 spesies ikan dengan hasil tangkapan keseluruhan sebanyak 99 ekor. Penelitian Baihaqi (2014) menunjukkan bahwa terdapat sebanyak 12 jenis spesies ikan yang tertangkap di sekitar rumpon ijuk. Ikan yang tertangkap di sekitar rumpon daun kelapa sebanyak 13 spesies ikan Total hasil tangkapan di sekitar rumpon dengan menggunakan pancing ulur adalah 429 ekor ikan, yaitu rumpon ijuk berjumlah 224 ekor ikan dan rumpon daun kelapa berjumlah 195 ekor ikan. 
Ikan yang dominan tertangkap pada rumpon atraktor ijuk adalah ikan selar kuning sebanyak $69 \%$, lemuru $23 \%$, kembung $6 \%$, layur $1 \%$ dan selar mata besar $1 \%$ dari total semua ikan yang tertangkap pada rumpon ijuk. Adapun ikan dominan tertangkap di sekitar rumpon atraktor daun kelapa adalah jenis ikan selar kuning sebanyak 52\%, lemuru 3\%, kembung 31\%, kuwe 4\%, kerong $4 \%$ dari total semua ikan yang tertangkap pada rumpon atraktor daun kelapa. Sedangkan hasil penelitian Baihaqi (2014) komposisi hasil tangkapan ikan pada rumpon ijuk didominasi oleh selar hijau sedangkan untuk rumpon daun kelapa didominasi oleh selar ekor kuning.

Perbandingan jumlah hasil tangkapan menggunakan pancing ulur pada rumpon ijuk dan rumpon daun kelapa yaitu total jumlah ikan yang tertangkap pada rumpon daun kelapa adalah sebanyak 29 ekor (2.423 gram) dan jumlah ikan yang tertangkap pada rumpon ijuk yaitu sebanyak 70 ekor (4.586 gram). Data perbandingan hasil tangkapan pada masing-masing rumpon dapat dilihat pada Gambar 4 dan Gambar 5. Oleh karena itu, berdasarkan jumlah hasil tangkapan baik dari segi jumlah ekor dan bobot hasil tangkapan ikan yang tertangkap di sekitar rumpon menunjukkan rumpon atraktor ijuk lebih efektif dibandingkan rumpon atraktor daun kelapa.

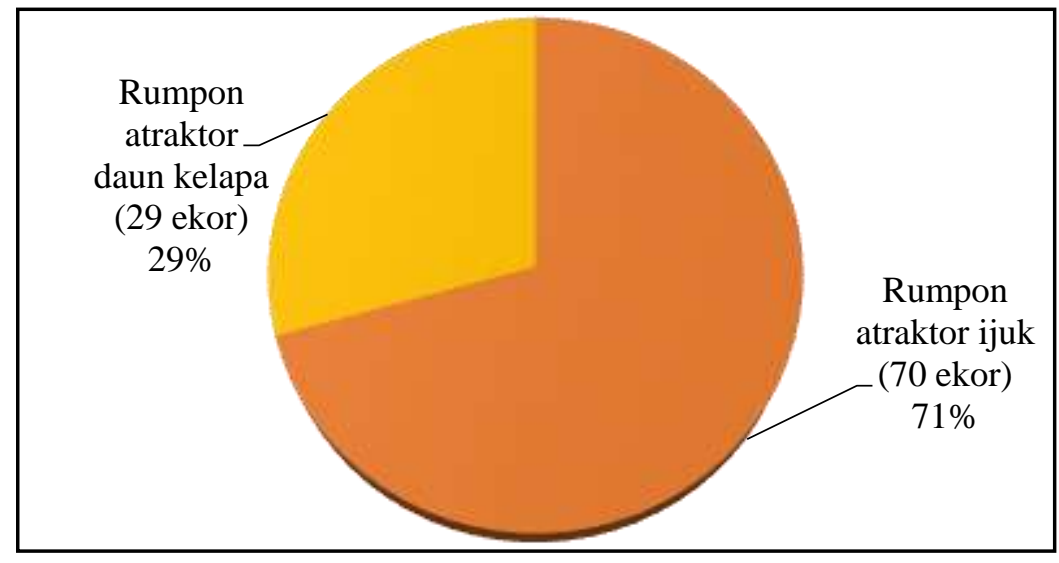

Gambar 4. Perbandingan hasil tangkapan (jumlah ekor) pada rumpon ijuk dan rumpon daun kelapa 


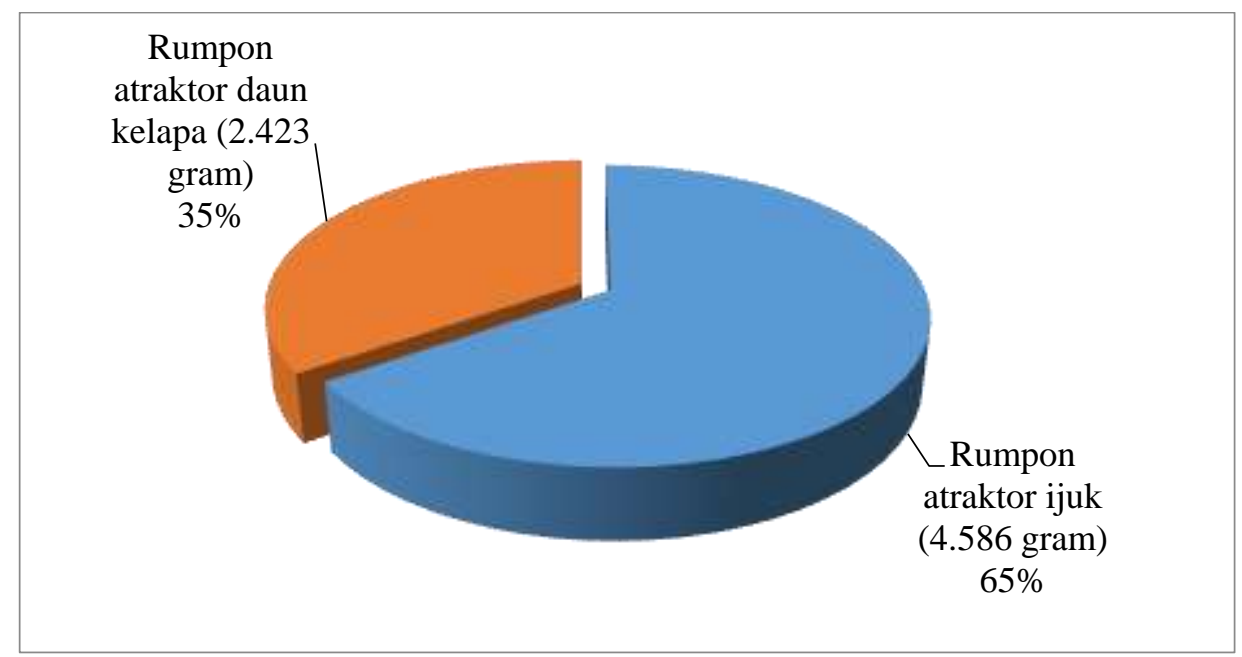

Gambar 5 Perbandingan bobot hasil tangkapan rumpon ijuk dan rumpon daun kelapa

\section{Kesimpulan}

Hasil penelitian menunjukkan komposisi hasil tangkapan pada rumpon atraktor ijuk dengan menggunakan alat tangkap pancing ulur yaitu 5 spesies ikan yang terdiri dari ikan selar kuning (Selaroides leptolepis), ikan lemuru (Sardinella lemuru), ikan kembung laki-laki (Rastrelliger kanagurta), ikan selar mata besar (Selar crumenopthalmus) dan ikan layur (Lepturacanthus savala). Sedangkan komposisi ikan yang tertangkap pada rumpon atraktor daun kelapa yaitu 7 spesies ikan yang terdiri dari ikan selar ekor kuning (Selaroides leptolepis), ikan kembung laki-laki (Rastrelliger kanagurta), ikan kuwe (Caranx sp), ikan kerong (Terapon jarbua), ikan tamban (Sardenella sirin), ikan talang-talang (Chorinemus tala) dan ikan biji nangka (Upenius mullocensin).

\section{Ucapan Terima Kasih}

Terima kasih kepada Kementerian Riset Teknologi dan Pendidikan Tinggi atas hibah program kemitraan masyarakat (PKM) tahun 2018 dan juga kepada tim teknis lapangan yaitu Abdul Karim (mahasiswa Prodi Perikanan Fakultas Perikanan dan Ilmu Kelautan Universitas Teuku).

\section{Daftar Pustaka}

Altinagac, U., Acarli, D., Begbusrs, C. R., and Oztekin, A. 2010. Comparison of Fish Agregating Devices (FADs) Having Different Atractors. Jurnal of Animal and Veterinary Advances. 9 (6) : 1026-129.

Baihaqi, L. I. 2014. Perbandingan karakteristik ikan pada rumpon dengan atraktor ijuk dan atraktor daun kelapa di Perairan Pulau Tunda Banten. Skripsi. Departemen Pemanfaatan Sumberdaya Perikanan Fakultas Perikanan dan Ilmu Kelautan Institut Pertanian Bogor. Bogor. 
Hasaruddin H., Ibrahim S., Hussin W. M. R. W., Ahmad W. M. A. W. \& Muchlisin Z. A. 2015. Artificial aggregating device for fish and squid eggs. AACL Bioflux, 8 (5), 832-837.

Hafinuddin dan Mahendra. 2016. Pemanfaatan ijuk (Arenga pinnata) sebagai alternatif natural atractor pada rumpon laut dangkal Perairan Meulaboh Kabupaten Aceh Barat. Laporan Tahun Terakhir Penelitin Dosen Pemula. Universitas Teuku Umar. Meulaboh.

Ibrahim, S., Hasaruddin, H., Hussin W. M. R. W. \& Ahmad W. M. A. W. 2014. Durability of coconut fronds as attactors for fish aggregating devices (FADs) : an observation based on leaf epidermis srtucture. AACL Bioflux. 7 (3) : 225-233.

Taquet, M. 2011. Artisanal ans industrial FADs: A question of scale. SPC Fisheries Newsletter, 136 (December), 35-45. 